\section{Questioning MDD}

I just finished reading "Coding for the Code" by Friedrich Steimann and Thomas Kuhne in Queue's December/January 2005 issue. I commend the authors for their balanced approach in presenting the issue using Dr. Pro and Dr. Con. It really highlighted the issues for the future of MDD (model-driven development).

Being a skeptic, I probably side more with Dr. Con, as MDD certainly has the feel of having been here before. The roles of modeler and transformation engineer sound an awful lot like analyst and programmer to me.

Pushing more of the development work to a modeler who doesn't have to understand the underlying technology seems unlikely to work. In my experience, the best programmers are also very strong at analysis. In some ways this false split reminds me of the JSP (JavaServer Pages) programming model where "page authors" used JSP tags and programmers wrote Java code. I've never seen this actually work in practice since the programmers ended up doing both Java and JSP tags and the page authors concentrated on visual design.

$$
\text { Nicholas Roeder, Calgary, Alberta, Canada }
$$

\section{The Economics of Outsourcing}

I've just read David Patterson's article on outsourcing (Curmudgeon, November 2005) and wholeheartedly agree.

\section{To submit a}

letter, E-MAIL US AT

FEEDBACK@ACMQUEUE.COM

There is another argument, however, against the possibility of "the sky falling," which is inherent within offshoring: the fact that it

exists because of the free market.

I recently attended a lecture on inshoring, where foreign workers (often already employees of the corporation) are flown in to staff projects. Their cost isn't that much less than workers locally sourced, once travel, local expenses, accommodations, etc. are taken into account. It's the sort of percentage that most would cut from their rate if it really meant no job otherwise and wouldn't completely outweigh other factors such as availability, locality, and the size of project.

A falling sky situation, where everything gets offshored, could occur only if there were a large disparity between inshored and offshored projects, and this remained constant. With the blending of the two worlds, with inshoring and the upside of the free market (Elbonian wage inflation), this can't happen. It may even improve lives in the Third World and ease pressure in the first.

$$
\text { Martin Wheatman, Preston, England. }
$$

We edit letters for content, style, and length. Q

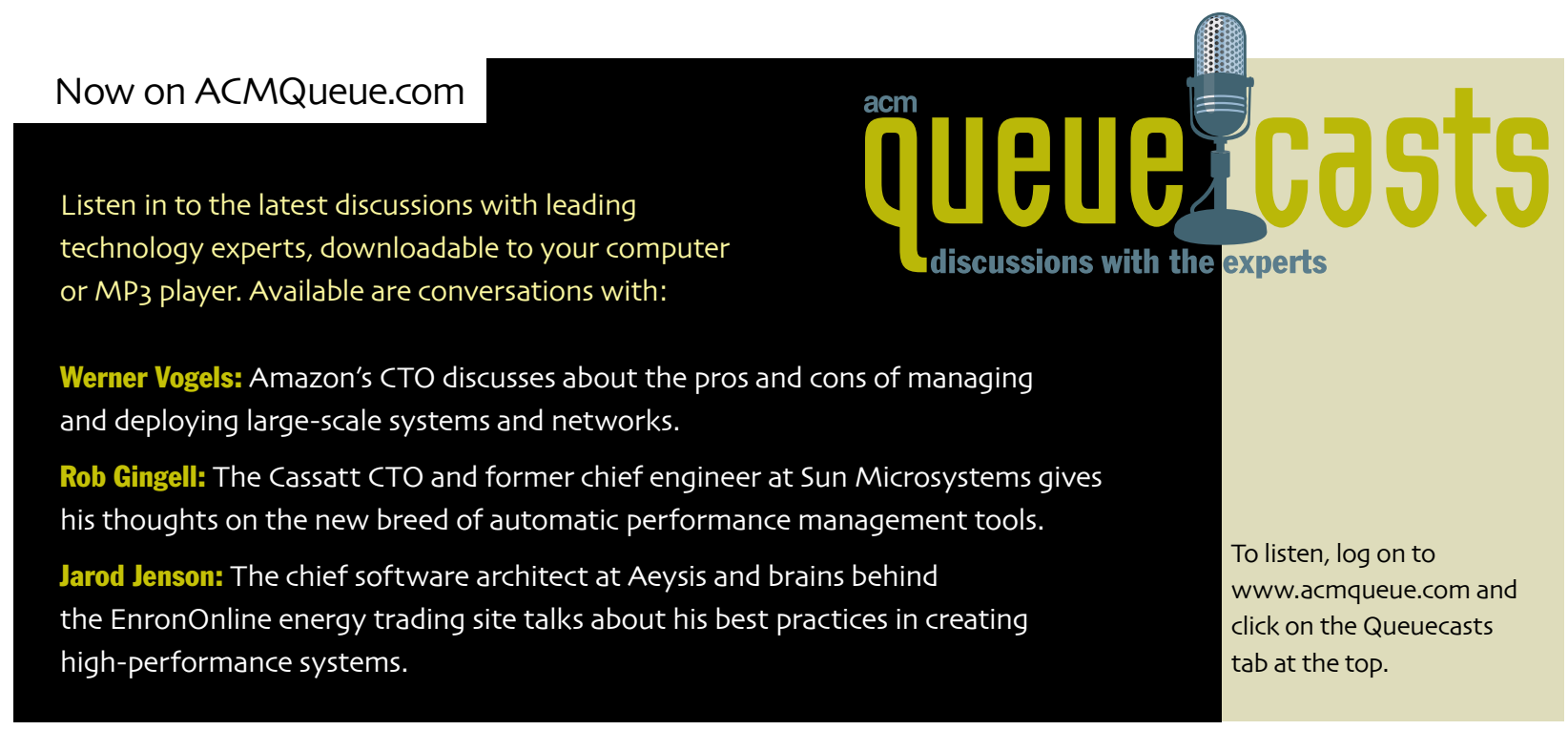

